\title{
Os Caminhos para o Desenvolvimento de uma Gestão Pública Inovadora no Brasil
}

\author{
ALESSANDRO CARLOS DA SILVA JUNIOR, \\ http://orcid.org/0000-0003-3467-9093 \\ MAGNUS LUIZ EMMENDOERFER \\ http://orcid.org/0000-0002-4264-8644
}

Gestão pública inovadora: um guia para a inovação no setor público. Antônio Isidro. Curitiba: CRV, 2018. 138p. ISBN: 978-85-4442566-4. DOI: 10.24824/978854442566.4.

A inovação no setor público emerge como uma alternativa para mudanças políticas, econômicas, tecnológicas e sociais do ambiente contemporâneo, aliada às reduções orçamentárias, maiores expectativas dos cidadãos, somada a necessidade de prestação de serviços públicos com maior qualidade pelas organizações públicas. Além disso, contribui para aumentar a confiança no Estado e promover a cidadania, a partir da inserção da sociedade e de parceiros (outras organizações públicas, privadas e do terceiro setor) no desenvolvimento de soluções inovadoras. Sendo assim, assume um papel importante na resolução de problemas complexos da administração pública.

O livro Gestão Pública Inovadora emerge a partir de dois contextos. O primeiro deles está relacionado ao crescimento da inovação nos países desenvolvidos como Dinamarca, Estados Unidos e Austrália, se tornando algo institucionalizado e cotidiano nas ações dos servidores públicos e dos governos dos países, a partir de modelos integrados, conceitos, processos, ferramentas e indicadores. Já o segundo, refere-se ao Brasil, país latino-americano, onde o assunto tem ganhado notoriedade por meio de esforços incessantes em nível municipal, estadual e federal, como observado em diferentes prêmios de inovação desde 1990, conforme apresentado pelo autor. Diante disto, Antônio Isidro lançou o livro com o objetivo de unir as duas 
trajetórias apresentadas e propor uma nova trajetória de inovação para o setor público, que contribua para o desenvolvimento de competências individuais e organizacionais, por meio de construtos teóricos e práticos que possam orientar as ações de gestores, servidores e equipes de inovação no setor público brasileiro.

A originalidade do livro se apresenta na forma em que o autor o constrói e aborda os conceitos, metodologias e modelos, a partir de esquemas analíticos, quadros, gráficos e estudos de caso que ilustram e demonstram de forma detalhada e compreensível, como os aspectos teóricos da inovação podem ser implementados na prática. Para o autor, a inovação se concretiza quando os governos criam arquiteturas, políticas e práticas organizacionais, e/ou quando geram e implementam ideias de algum impacto frente às demandas sociais. Sendo assim, pode ser definida como "um processo que requer indivíduos e organizações com capacidades para permitir a identificação e implementação de ideias, sistematizadas para o contexto de sua aplicação, servindo como soluções para problemas que implicam melhor desempenho em termos de eficiência, eficácia e valor dos resultados do setor público [e/ou privado] para a sociedade" (EMMENDOERFER, 2019, p. 1, grifo nosso).

Ademais, a forma como o livro se estrutura, iniciando com um contexto geral da inovação no setor público, através dos principais conceitos e modelos teóricos encontrados na literatura, até se chegar na proposição de um Ecossistema de Inovação, auxilia o leitor como um guia para compreender o processo de inovação de forma sistêmica e institucionalizada, além de auxiliar no desenvolvimento de competências para gestores e servidores públicos inovarem.

Antônio Isidro da Silva Filho é especialista em pessoas e inovação. Possui PhD em administração pela Universidade de Brasília (UnB), MBA em Gestão de Pessoas pela Fundação Getúlio Vargas (FGV) e formação internacional em gestão pela HEC Montreal (Canadá). Atualmente é coordenador do LineGov| UnB - Laboratório de Inovação e Estratégia em Governo da Universidade de Brasília e atua como professor dos cursos de graduação, mestrado e doutorado acadêmico em Administração e do Mestrado Profissional em Administração Pública pela UnB. Além disso, é líder de projetos de pesquisa e desenvolvimento em inovação, estratégia, gestão de 
pessoas e de lideranças. Dessa forma, a sua experiência nas áreas de inovação e gestão de pessoas ficam evidentes ao longo da obra, a partir dos construtos teóricos e práticos apresentados que se direcionam a acadêmicos, gestores, servidores e equipes de inovação no setor público.

A obra avança na literatura sobre inovação ao oferecer uma espécie de orientação guiada do tipo manual, no qual demonstra insumos para que gestores, servidores públicos e acadêmicos possam desenvolver inovações no setor público ou contribuir para a construção de uma abordagem sistêmica e institucionalizada da inovação. Mesmo que a configuração da obra denote um manual que prescreve ações sistematizadas para a inovação, isso não limita o seu alcance ou contribuições como uma visão mais detalhada dos processos a serem desenvolvidos, assim como valorizar cada etapa da inovação no setor público. Sendo assim, além de atingir os indivíduos do setor público e acadêmicos que estudam o assunto, a obra pode ser de interesse da sociedade como um todo, visto que apresenta de forma didática e compreensível, aspectos que podem gerar insights nos cidadãos para o desenvolvimento de soluções inovadoras, sobretudo em ambientes de coprodução e cocriação de serviços públicos, cada vez mais comuns no governo brasileiro e nos países do mundo.

A obra é composta por uma introdução que apresenta os aspectos que caracterizam a inovação e sua adoção em organizações públicas e privadas, apresentando as congruências e diferenças existentes nas estruturas das organizações, o que acarreta em diferentes fins para os projetos inovadores. Além disso, o autor aborda os principais valores/fundamentos de uma gestão pública inovadora, em que o amor, a felicidade, a esperança, o trabalho e a doação demonstram ser aspectos importantes para se concretizar uma gestão pública inovadora e induzir outros valores humanos, organizacionais e sociais que moldam o Ecossistema de Inovação no Setor Público. Tais valores e características organizacionais são importantes para mobilizar os fatores humanos, que são valorizados no decorrer do livro como importantes para se colocar em prática em uma gestão pública inovadora.

Dessa forma, o autor defende que a inovação deve ser considerada um valor público e que deve ser compartilhada entre polí- 
ticos, gestores e servidores públicos. Para o autor o valor público no contexto da inovação pressupõe que as políticas públicas, os processos organizacionais e os serviços públicos ofertados nunca sejam os melhores possíveis para um país, visto que a oportunidade de inovar e a melhorar continuamente a administração pública, tem o potencial de atrair vários indivíduos para o serviço público.

Somado a isso, há quatro partes que formam uma espécie de passo a passo para a construção de um Ecossistema de Inovação no Setor Público, sendo esse considerado um último estágio na qual a inovação se torna institucionalizada e natural no cotidiano das organizações públicas. A primeira parte do livro, composta por quatro capítulos, apresenta como objetivo oferecer um panorama da produção de conhecimentos acerca da inovação no setor público, descrevendo os seus principais elementos conceituais. Para tal, são abordados os fundamentos da gestão pública inovadora, que demonstram a importância do setor público como usuário e fomentador da inovação, mas também como um agente propositor de inovações, que poderão aumentar a confiança e a legitimidade do Estado frente a sociedade, cidadãos e usuários dos serviços públicos. Diante disto, são apresentadas as alternativas teóricas de interpretação da inovação no setor público e as suas tipologias e formas de ocorrência, que se desenvolvem levando em consideração os indutores, facilitadores e as barreiras para a inovação, e podem ser individuais, organizacionais e/ou institucionais.

Os conceitos abordados na primeira parte do livro têm o objetivo de demonstrar que a implementação de novos elementos e o processo de mudança são centrais quando se trata em inovação. Além disso, as tipologias apresentadas descrevem as características da inovação, tais como sua natureza, conteúdo, modo de implementação e orientação estratégica nas organizações públicas, podendo ser complementares e oferecer diferentes direcionamentos. Dessa forma, a parte inicial do livro demonstra ao leitor uma visão geral do assunto, sobre a importância de se inovar no contexto organizacional e os benefícios que podem ser alcançados, a partir do engajamento entre o setor público, a sociedade e demais organizações que atuam na prestação de serviços públicos à população. 
A segunda parte do livro é composta por nove capítulos. Define-se como objetivo apresentar um panorama geral dos principais modelos de inovação no setor público presentes na literatura e em relatórios técnicos, seus elementos constituintes e peculiaridades. Para tal, são apresentados aspectos teóricos da inovação no setor público, demonstrando a evolução dos conceitos, que inicialmente se associavam às ideias de desenvolvimento econômico e evolutivas de Schumpeter. Posteriormente, passaram a ser influenciados pelas teorias das organizações, ao conceituar a inovação no setor público de forma semelhante à inovação no setor privado. E atualmente, é considerada uma teoria emergente (autóctone), particular para o setor público se distanciando da inovação no setor privado. Tal distanciando, segundo o autor, está relacionado ao poder da autoridade pública, o fato de as inovações levarem a mudanças evolutivas nas barreiras e facilitadores típicos do setor público, e por se utilizarem de diferentes meios, recursos, relacionamentos e instituições.

A perspectiva apresentada, leva em consideração aspectos institucionais, normativos e relacionais que são próprios do setor público, guiados para o aumento do bem-estar e a melhoria da qualidade de vida dos cidadãos. O autor apresenta o Projeto de Inovação no Setor Público (PUBLIN) como um primeiro direcionamento mundial para se inovar no setor público, inspirando os modelos de inovação nos Países Nórdicos, Inglaterra, Austrália, Coreia do Sul, países-membro da Organização para a Cooperação e Desenvolvimento Econômico (OCDE), Estados Unidos e Chile, apresentados na obra. O projeto tinha como objetivo reunir conhecimentos que orientassem o desenvolvimento de políticas nacionais de inovação no setor público, inspirando diversos países a desenvolverem modelos próprios, associando a inovação a uma política de aprendizagem no setor público, ao congregar diversos atores, parceiros, capacidades, recursos e competências, para aumentar a efetividade dos processos inovativos. Contudo, observa-se que o livro em voga se dedica mais a apresentação de projetos de inovação como diretrizes para o desenvolvimento de ações em prol da inovação em nível nacional, mas não se aprofundando em peculiaridades da gestão de projetos de inovação em governos locais ou em nível municipal (Cf. SAMPAIO; EMMENDOERFER, 2020). 
Os modelos apresentados servem de inspiração teórica e prática para o desenvolvimento de soluções inovadoras nos demais países do mundo, através de aspectos institucionais, barreiras, facilitadores e alternativas de capacitação dos indivíduos para a inovação. No Brasil, embora não exista um framework específico que oriente especificamente a inovação no setor público, o Programa Nacional para a Gestão Pública e Desburocratização (GesPública) que vigorou durante doze anos, procurou orientar as organizações públicas para o desenvolvimento de soluções para a melhoria da qualidade dos serviços e aumento da competitividade organizacional, até a sua revogação em 2017. Atualmente no Brasil, os esforços de inovação são esparsos e ficam a cargo de redes e laboratórios de inovação atuarem de forma cooperativa na proposição de serviços públicos e políticas públicas, buscando melhorar a forma como os governos funcionam e atuam, conforme apresentado pelo autor.

Na terceira parte do livro, composta por seis capítulos, é apresentada uma abordagem estratégica da inovação no setor público, enfatizando os fundamentos, a dinâmica e a avaliação de práticas e capacidades organizacionais orientadas à inovação. Para tal, o autor apresenta o Modelo Integrado de Gestão Pública Inovadora (GESPUBLIN). Este modelo é oriundo de intensas revisões teóricas e práticas, e tem o objetivo de contribuir para a concretização de agendas políticas de inovação nas administrações públicas e governos. Ele é composto por quatro dimensões (Ambiente de Inovação, Capacidade de Inovação, Atividades de Inovação e Resultados da Inovação); quatro níveis de maturidade (Inovação Reativa, Inovação Ativa, Inovação Proativa e Inovação Contínua), e cinco etapas para a implementação de práticas da gestão pública inovadora (Diagnóstico, Desenvolvimento, Implementação, Avaliação e Melhoria).

$\mathrm{O}$ autor apresenta de forma clara e didática, por meio de quadros, cada um dos elementos formativos do GESPUBLIN, demonstrando que em cada um dos níveis de maturidade as dimensões vão se tornando cada vez mais institucionalizadas e recorrentes no dia-a-dia das organizações públicas. Os níveis variam de uma inovação restrita a esforços individuais, descontinuados, até se chegar em um último nível (Inovação Contínua), no qual os esforços são direcionados para gerenciar e atuar sobre as variáveis ambientais, de 
modo a controla-las, e as organizações atuarem de modo integrado com os stakeholders, a partir do compartilhamento de recursos.

Buscando ilustrar como a inovação se manifesta em cada um dos níveis de maturidade, o autor apresenta exemplos de práticas de inovação de modo a encorajar o leitor a desenvolvê-las no âmbito público, e partir daí, avaliar a Gestão Pública Inovadora, no intuito de identificar o nível de maturidade, os gaps ou lacunas das práticas de inovação e o potencial de inovação da organização. A partir dos elementos abordados na terceira parte do livro, o autor procura, então, ilustrar como deve se desenvolver uma gestão pública inovadora para se chegar na proposição de uma Ecossistema de Inovação no Setor Público, que conforme mencionado, seria um último estágio, no qual a inovação se tornaria algo sistêmico e difundido por todas as organizações públicas.

Na quarta parte do livro, composta por quatro capítulos, o autor oferece essa visão sistêmica da inovação no setor público, enfatizando os fundamentos, a dinâmica e a avaliação de práticas e capacidades organizacionais orientadas à inovação. Para tal, com a ideia de um Ecossistema de Inovação no Setor Público, tem como objetivo oferecer direcionamentos e capacitar as organizações para que a inovação seja uma prática contínua e sistemática, e assim, possa gerar maior valor para os cidadãos. Dessa forma, apresentam-se os elementos constitutivos do Ecossistema, no qual reconhecem que a inovação é um fenômeno multinível, multidimensional, complexo e social.

Os elementos que caracterizam e estruturam o Ecossistema são: ambiente de inovação (indutores, barreiras, facilitadores e objetivos da inovação), desenvolvimento de pessoas e competências para a inovação (escolas de inovação), reconhecimento e valorização de esforços de inovação (prêmios de inovação), gestão integrada de projetos de inovação (escritórios de inovação), incubação e sustentação de ideias inovadoras (laboratórios de inovação) e produção de conhecimento sobre a inovação (observatórios de inovação). A partir dos elementos constituintes e estruturantes de um Ecossistema de Inovação, a aprendizagem se destaca como um importante elemento para uma gestão pública inovadora, pois é um elemento que desafia a continuidade e estabilização das organizações, propondo alterna- 
tivas para a adaptação e mudança de comportamentos individuais e coletivos nas organizações do setor público.

Por fim, destaca-se a importância da avaliação dos Ecossistemas de Inovação no Setor Público, em que elementos como produtos, atividades, recursos, resultados de curto prazo, resultados intermediários e resultados de longo prazo, conforme apresentado pelo autor, contribuem para a criação de uma cultura da inovação e para o engajamento direto de pessoas, organizações e instituições nos processos criativos, que resultarão em melhores serviços públicos e melhora na qualidade de vida dos cidadãos.

Conclui-se que os elementos abordados no livro Gestão Pública Inovadora, contribuem para a compreensão da inovação como um elemento/instrumento que merece destaque no contexto das organizações públicas, pela sua capacidade de influenciar não só na melhoria e entrega dos serviços, mas também na geração de valor para a sociedade. As inovações perturbam o status quo estabelecido no setor público, por meio da mudança de comportamento, sobretudo individuais e institucionais, e a busca pela sua inserção no cotidiano das práticas do setor público, deixando de ser eventos isolados e específicos para se tornar algo sistêmico. Tal fato contribui para aumentar a legitimidade e a confiança dos cidadãos para com as organizações públicas. Desta forma, o público que se beneficiariam da obra seriam os gestores públicos, os acadêmicos (estudantes de graduação e pós-graduação e docentes), assim como os cidadãos em geral, visto que apesar de apresentar alternativas para decisão e insumos teóricos que possam embasar estudos sobre a inovação no setor público, a forma didática e simples de apresentar o conteúdo, pode ser de interesse e de fácil compreensão pelos indivíduos que se interessam pelo tema.

Por fim, destaca-se que o livro extrapola os objetivos propostos, ao gerar provocações e oferecer subsídios teóricos e práticos para o desenvolvimento de uma gestão pública orientada para a inovação, fazendo uso do pensamento visual nas imagens empregadas a fim de tornar a comunicação mais eficaz. Como limitação, tem-se o fato de a inovação, sobretudo no setor público brasileiro, ainda estar associada a atividades individuais ou a órgãos específicos, não sendo considerada algo natural, comum e difundido no cotidiano 
das práticas do setor público, nos mais diferentes níveis hierárquicos e nas instâncias governamentais. No entanto, o livro se demonstra um importante instrumento, ou um primeiro passo, para estimular a adoção dessas práticas nas organizações públicas.

\section{REFERÊNCIA}

ISIDRO, Antônio. Gestão Pública Inovadora: um guia para a inovação no Setor Público. Curitiba: CRV, 2018. 138p.

\section{Referências complementares}

EMMENDOERFER Magnus Luiz. Innovation, Brazil. In: FARAZMAND, Ali. (ed.) Global encyclopedia of Public Administration, Public Policy, and Governance. Springer, Cham, 2019. DOI: https://doi.org/10.1007/978-3-319-31816-5_3764-1.

SAMPAIO, Vanderlei da Silva; EMMENDOERFER, Magnus Luiz. Gestão de projetos de inovação: as premissas do Project Management Institute aplicadas ao Setor Público Municipal. 1. ed. Viçosa: IPPDS/UFV, 2020. v. 1. 92p.

* Agradecimentos à Coordenação para o Aperfeiçoamento de Pessoal de Nível Superior (CAPES - financiamento 001).

Recebido em: 11-3-2021

Aprovado em: 29-7-2021

Avaliado pelo sistema double blind review.

Editor: Coordenação do PPGA/UMESP

Disponível em http://mjs.metodista.br/index.php/roc 